\title{
Continuous Ice Nuclei Measurements Made During Pulsed Cloud Seeding
}

\author{
Charles E. Robertson \\ E. Bollay Associates, Inc., Boulder, Colo. \\ (Manuscript received 6 February 1969)
}

\begin{abstract}
In a cloud seeding program, it is necessary to know what meteorological conditions are controlling the travel of artificial ice nuclei. While it is obvious that they will travel with the air currents, it is difficult to determine if the currents will travel to the desired area, and how much time is taken to transport the nuclei from the generator to the target area. Silver iodide particles were generated in a cyclic manner from groundbased generators, while continuous observations of ice nuclei were made on the surface in the target area. Observations show the surface wind velocity at the generator site to be the primary factor controlling the particle travel. However, nuclei concentrations have been observed to remain low even though the wind velocity was favorable for detection. This may be due to the silver iodide particles nucleating the cloud to form ice crystals, which do not enter the nucleus counter.
\end{abstract}

\section{Introduction}

There are various reports in the literature concerning ice nuclei measurements as they relate to cloud seeding operations. Boucher (1956) has analyzed concentrations of nuclei during Operation Overseed; he found in approximately half the seeded cases that significant increases in nuclei count were observed, the maximum concentrations being 10-100 liter ${ }^{-1}$ effective at $-20 \mathrm{C}$. Negative results were attributed to improper targeting or stability influences. More recently, Reinking and Grant (1968) reported on five seasons of nuclei observations during seeding operations. They found an average concentration of 13 liter $^{-1}$ at $-20 \mathrm{C}$. In twothirds of their cases, nuclei were detected in amounts considerably above background.

The generator operations in these and most other investigations have been continuous, to produce a maximum effect on the supercooled clouds. The design characteristic of the Park Range Atmospheric Water Resources Program utilizes pulsed silver iodide seeding of clouds and has done this with a square-wave frequency of from $0.25-1.0$ cycle $\mathrm{hr}^{-1}$. Downwind measurements of snowfall rate are then correlated with this seeding pattern as a test for precipitation changes. To make the correlation, it is necessary to know the length of time required for the potential ice nuclei to travel from the generator site to the location of the snowfall measuring equipment. This is done by monitoring the free air ice nuclei concentration. This paper describes the results of ice nuclei measurements made during pulsed seeding.

\section{Topography and equipment}

The topography of the Park Range area in northwestern Colorado is shown in Fig. 1. The Skyfire high- output generators $\left(5 \times 10^{14}\right.$ nuclei $\mathrm{gm}^{-1}$ or $2 \times 10^{13} \mathrm{sec}^{-1}$ at $-20 \mathrm{C}$ ) are located on $2.5 \mathrm{~km}$ MSL Emerald Mountain, along with a wind sensor mounted on a $30.5 \mathrm{~m}$ tower. Separating the generator site from the Park Range is a $5 \mathrm{mi}$ wide valley (elevation $2.07 \mathrm{~km}$ MSL). Ice nuclei observations are made at Rabbit Ears Pass (most frequently) and Buffalo Pass. The locations, relative to the generator site, are given in Table 1 . Fourteen miles west of Emerald Mountain, at Mt. Harris (22.5 km west of Mt. Emerald), is a Nike-Ajax radar with which upper air data are obtained.

The concentration of airborne ice nuclei is measured with an NCAR type acoustical ice nucleus counter operating at $-20 \mathrm{C}$. Details of this counter have been given elsewhere (Langer et al., 1967), but the following should be noted: first, it operates continuously and automatically; and second, nuclei which are part of a snow crystal are not taken into the instrument. Background nuclei concentrations measured with this counter at this location show $95 \%$ of the observations are less than 0.2 liter $^{-1}$.

\section{Results of nuclei measurements}

An examination of 35 storm periods during the winter of 1966-67 have shown the occurrence of three types of nuclei concentration characteristics.

\section{a. Type I}

Type $I$ is what might be called the desired case, i.e., the nuclei concentrations observed in the target area reflect the cyclic nature of the seeding, and an increase in nuclei can be related to a specific seeding period. This occurs only when the winds above the target level and at the surface are aligned (within certain limits) 


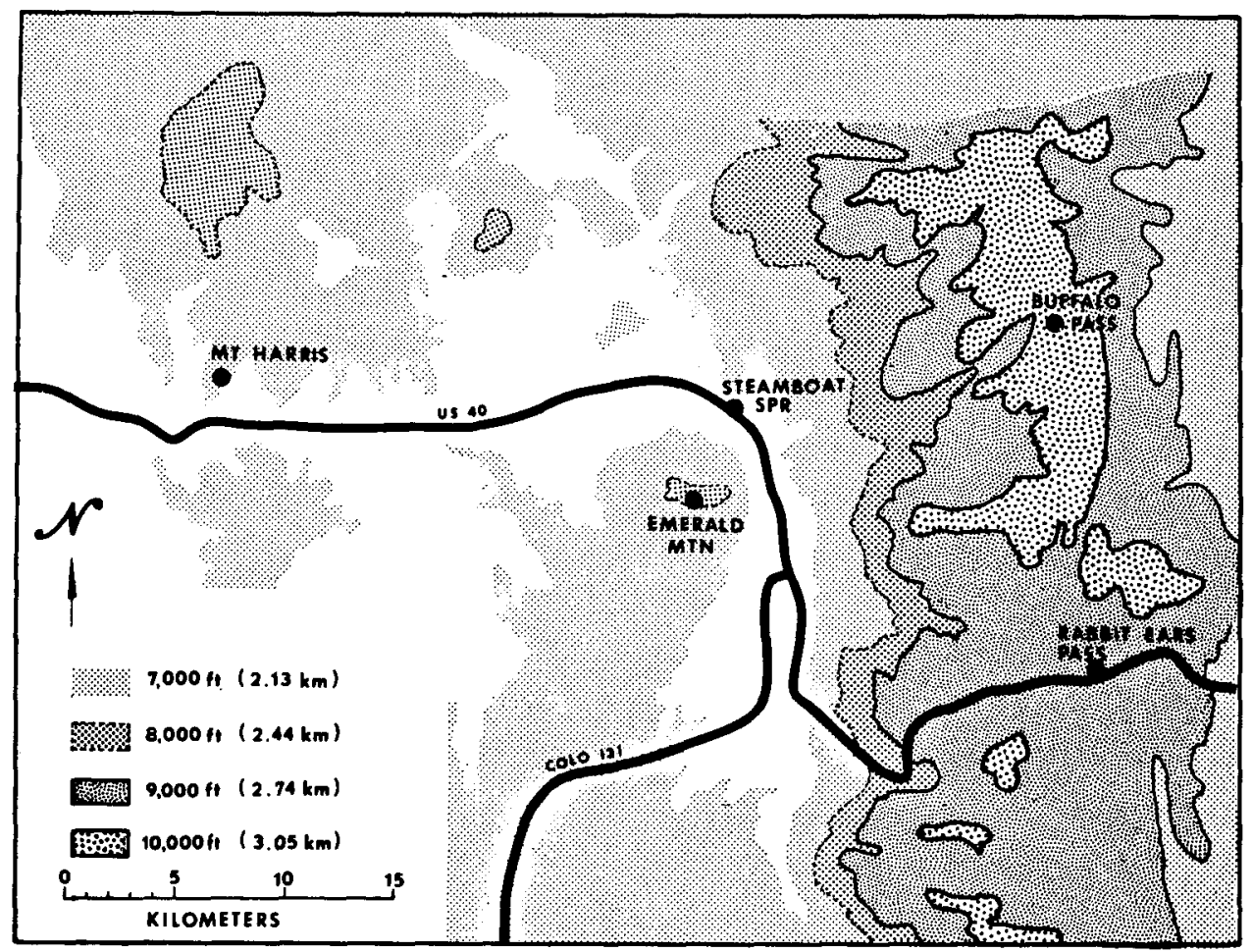

FIG. 1. Topographic map of the park range area of northwestern Colorado.

with the observing site. The azimuthal limits for detection at Rabbit Ears are $270^{\circ}$ and $350^{\circ}$, and for Buffalo Pass, $210^{\circ}$ and $270^{\circ}$. This does not mean the plume width is $80^{\circ}$ but only that nuclei concentrations have been observed to increase when the wind direction is within these limits. This type of nuclei observation occurred during $40 \%$ of the seeding time, and specifically on 7 December 1966 (Fig. 2). The top of the figure shows the $3.36-\mathrm{km}$ winds which are just above the crest of the Park Range. Below these are the winds (hourly means) measured atop a $30.5 \mathrm{~m}$ tower at the generator site. The solid bars indicate the seeding

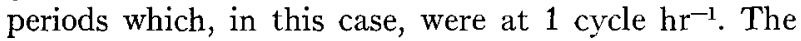
open rectangles represent the time during which the nuclei were forecast for the Rabbit Ears observing site.

The forecast was made by projecting the nuclei according to the surface wind speed at the release site. The travel time is determined from the travel distance and wind speed at the generator site. This model of transport was found to represent the movement of the

TABLE 1. Locations of nuclei counters relative to the Emerald Mountain generator site.

\begin{tabular}{cccc}
\hline \hline Location & $\begin{array}{c}\text { Elevations } \\
(\mathrm{km})\end{array}$ & $\begin{array}{c}\text { Distance } \\
(\mathrm{km})\end{array}$ & $\begin{array}{c}\text { Most favorable } \\
\text { wind direction }\end{array}$ \\
\hline Rabbit Ears & 2.9 & 19.3 & $292^{\circ}$ \\
Buffalo Pass & 3.12 & 18.5 & $243^{\circ}$ \\
\hline
\end{tabular}

nuclei in most of the cases classified as Type I. The notable exceptions occurred when 1) the surface wind $<16 \mathrm{~km} \mathrm{hr}^{-1}$, in which case the transport time was better given by the $3.36-\mathrm{km}$ wind, and 2 ) when the difference between the $3.36-\mathrm{km}$ and surface winds $>56$ $\mathrm{km} \mathrm{hr}^{-1}$; then an average of the two speeds was the best indicator.

The use of the surface wind as a transport determining parameter agrees with the results of Fuquay (1964), who found the wind statistics at the release

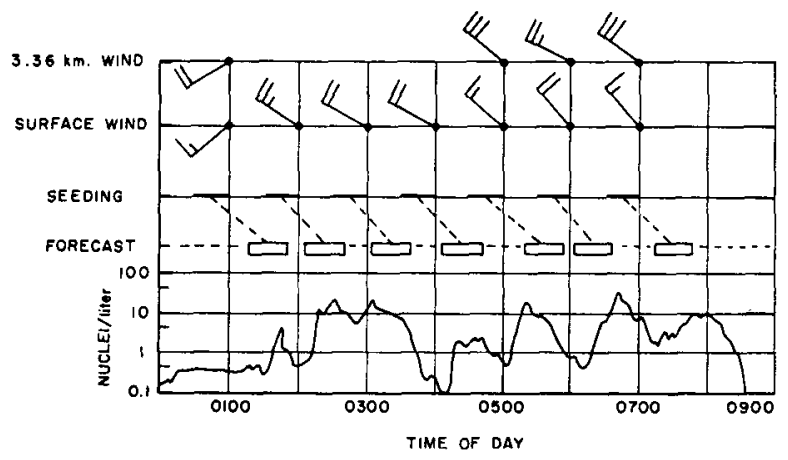

FIG. 2. Ice nuclei concentrations on 7 December 1966 reflecting the cyclic nature of the generator operation. Seeding was done $19.3 \mathrm{~km}$ upwind with a frequency of $1 \mathrm{cycle} \mathrm{hr}^{-1}$. The top winds are those at $3.36 \mathrm{~km}$, the next are the generator site surface winds. The solid bars indicate the times of generator operation and the open rectangles the time during which the nuclei were forecast to be at the observing site. 
point to be the primary parameter controlling the plume spread for large distances downwind. The terrain in his work is described as "gently rolling" so the same principles might not apply to the mountainous terrain of the Park Range even though the results are similar. On the other hand, it appears to be in disagreement with the results of Auer et al. (1968), who state the best predictor is "the direction and speed (with its dependence upon the stability) of the wind within the layer $450 \mathrm{~m}$ above the prevailing terrain. ..." This apparent disagreement can be reconciled by noting, in Fig. 1, that Emerald Mountain, at $2.5 \mathrm{~km}$, is nearly $450 \mathrm{~m}$ above the surrounding valley terrain.

It is obvious that there is a peak in nuclei concentration corresponding to each forecast plume. Table 2 shows the transport time for each of the seven pulses, both calculated from the wind speed and from the plot of nuclei concentration vs time. Relatively large differences are seen for the travel time of individual pulses; however, the averages are essentially the same.

An initial inspection of the first seeding period indicates that the winds, plotted as hourly averages, came from the wrong direction at both levels for nuclei to reach at the Rabbit Ears site; however, an inspection of the original surface wind data shows a wind shift from $190^{\circ}$ to $310^{\circ}$ occurred just after 0100 MST.

It is important to point out, with a travel distance of $16.3 \mathrm{~km}$, that one cycle per hour seeding does not allow sufficient time for the nuclei concentration to return to background. Only between the third and fourth cycles does this occur. Since it is desired, in the Park Range Program, for the concentration to return to background, the frequency of the seeding was decreased to $0.25 \mathrm{cycle} \mathrm{hr}^{-1}$. Prior to this, the generator site was relocated to Mt. Harris (42 km from Rabbit Ears) to give the nuclei a greater in-cloud residence time before they reached the target area. Fig. 3 shows the case of 13-14 March 1968. Prior to 2200 on 13 March, the wind directions were wrong for detection at Rabbit Ears but then shifted to the proper direction. Since the surface
TABLE 2. Transport time, calculated and real, in minutes.

\begin{tabular}{ccc}
\hline $\begin{array}{c}\text { Pulse } \\
\text { number }\end{array}$ & $\begin{array}{c}\text { Calculated } \\
\text { (from aerovane) }\end{array}$ & $\begin{array}{c}\text { Real } \\
\text { (from nuclei data) }\end{array}$ \\
\hline 1 & 52 & 62 \\
2 & 40 & 42 \\
3 & 40 & 30 \\
4 & 40 & 45 \\
5 & 55 & 40 \\
6 & 36 & 52 \\
7 & 52 & 65 \\
Average & 45 & 48 \\
\hline
\end{tabular}

speeds $<16.1 \mathrm{~km} \mathrm{hr}^{-1}$, the $3.36-\mathrm{km}$ speeds were used in the forecast. Under these conditions, the concentrations did return to background.

\section{b. Type II}

In some respects, the simplest case to explain occurs when the top of an inversion is between the generator and the observing sites. Twenty per cent of the 1966-67 data fell into this category and this occurred even during precipitation periods. On 4 January 1967 (Fig. 4) an inversion was present and manifested itself by the light southerly winds (changing to northerly) at the surface while moderate westerlies occurred at $3.36 \mathrm{~km}$. No pulsing is evident. It is interesting to note that the nuclei concentration was on the order of 1 liter $^{-1}$ higher than during periods of no seeding. An examination of all the inversion cases showed that when the winds above the inversion were from the northwest quadrant, the nuclei count at Rabbit Ears usually ran 1-2 liter $^{-1}$; when it was from the southwest quadrant, it was $0.8-1$ liter ${ }^{-1}$. Evidently, some of the seeding agent does reach the ridge and this can be interpreted as evidence of some form of vertical transport through the inversion. Whether this is in the form of weak thermals breaking through the top, particulate diffusion, or a leaking where the lid of the inversion meets the mountains, is not known.

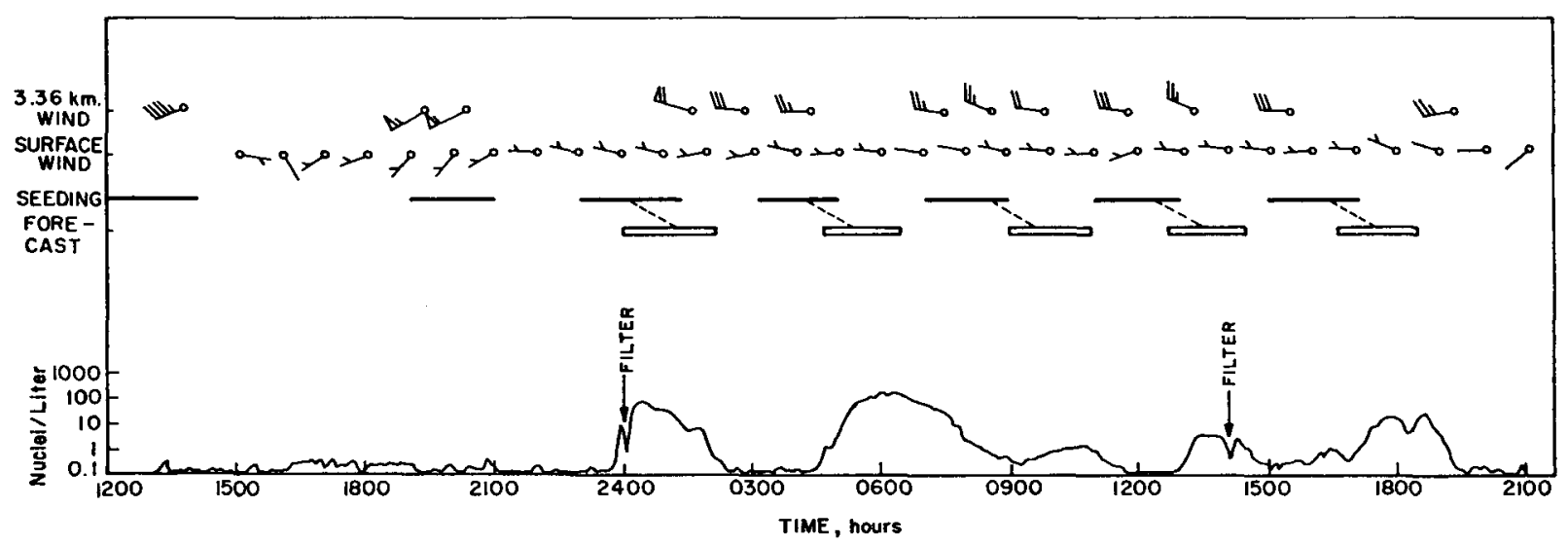

FIG. 3. Ice nuclei concentrations observed on 13-14 March 1968. Seeding was done $42 \mathrm{~km}$ upwind with a frequency of $0.25 \mathrm{cycle}$ hr ${ }^{\mathbf{1}}$. 


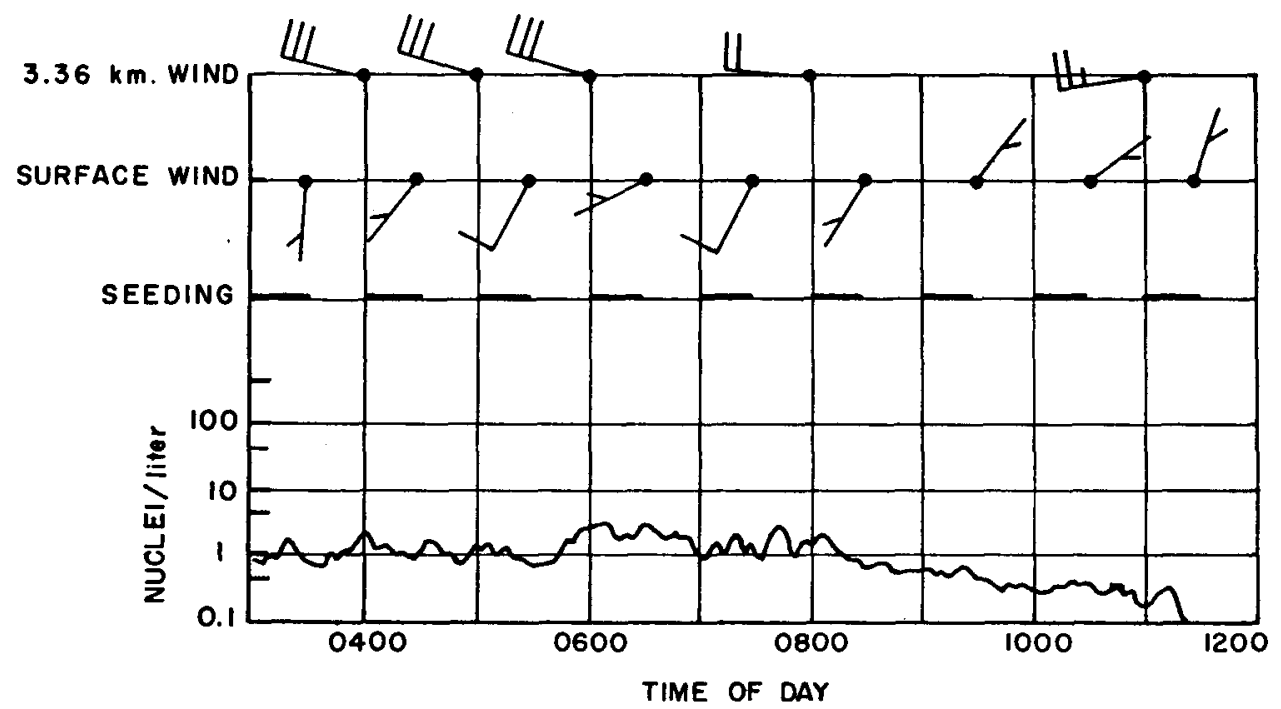

FIG. 4. Ice nuclei concentrations observed on 4 January 1968. An inversion was present during this entire period. Note the concentrations are $\sim 1$ liter $^{-1}$, indicating some type of transport through the inversion.

When an inversion dissipates; the large number of nuclei which has accumulated are released and carried by the prevailing winds to the target area. This occurred on 25 January 1967 as shown in Fig. 5. The inversion existed until 1230 , but then there was a wind shift and speed increase at the generator site, indicating dissipation of the inversion. Very high nuclei concentrations, up to 350 liter $^{-1}$, were subsequently measured between 1310 and 1600 MSTT. $^{\prime}$

\section{c. Type III}

1. The most difficult case to explain occurred in nearly $20 \%$ of the observations. The observed meteorological conditions (especially wind velocity) are very similar to those in Type I, but whereas Type I reflects the cyclic nature of the seeding, there is no evidence of pulsing in Type III and the nuclei content of the air remains near 1 liter $^{-1}$ or less. This case is demonstrated in Fig. 6 (5-6 January 1967) where the winds above ridge level and the surface winds were both in the proper direction for detection while few nuclei were detected.

Three hypotheses have been set forth to explain the absence of nuclei in the apparently favorable cases: 1 ) they are being swept upward out of the surface layer by local vertical motions; 2 ) the silver iodide particles are being scavenged by the falling snow; and 3) they are

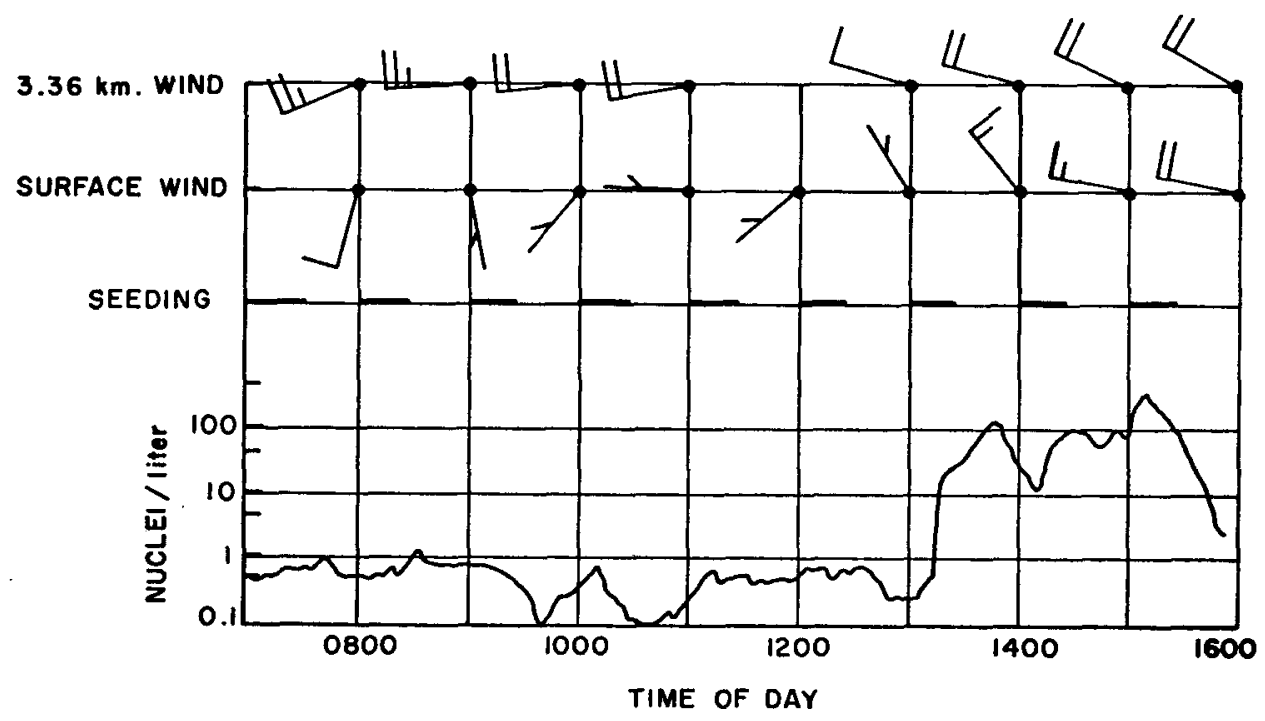

FIG. 5. Concentrations on 25 January 1968, showing the high concentrations which resulted when an inversion broke at about $1230 \mathrm{MST}$. 


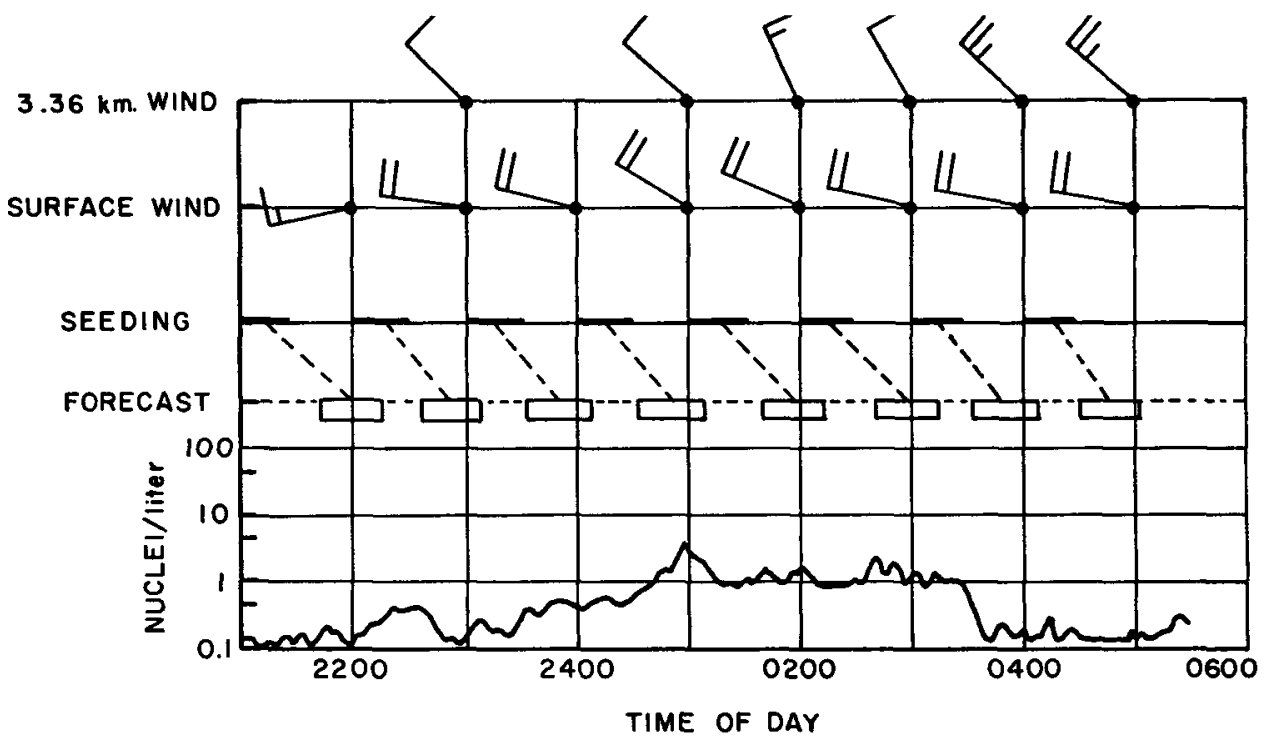

FIG. 6. Concentrations on 5-6 January 1967. No increases in nuclei count were observed even though the wind direction was proper for detection.

being used as ice nuclei and therefore are not observed by the nuclei counter.

The relative strength of each hypothesis can be determined by examining some ancillary data. A dual tracer experiment was conducted in the early hours of 6 January. Lithium sterate powder, inert as both a condensation and ice nucleus, was emitted alongside the silver iodide particles and were detected at Rabbit Ears by an aerosol photometer (Hogan and Rich, 1968) in concentrations two orders of magnitude above background. Considering the relative outputs of the two chemicals, high concentrations of artificial ice nuclei should have been observed. Similar results were found in January and February 1968 and have been discussed by Hogan et al. (1969). These observations tend to eliminate the local vertical motion hypothesis as both chemicals have similar aerodynamic characteristics. It is quite often that high nuclei concentrations are accompanied by high snowfall rates (the snowfall rate during much of the high count period of Fig. 5 was $0.2 \mathrm{~mm}$ of water $\mathrm{hr}^{-1}$ ). Hence, the second hypothesis weakens. This leaves the hypothesis that silver iodide particles are used as nuclei to create snow as the most probable. The problem is now to define the meteorological conditions which are different during observations of Types I and III and therefore allow the particles to be used as nuclei in one case and remain in the free air in the other. This is under study.

\section{Conclusions}

The one-dimensional (longitudinal) diffusion pattern is relatively simple in the physical environment utilized by the Park Range Program and a model for nuclei transport has been developed which is based mainly on the surface wind speed at the release site. In cases of low surface speeds or high shear in the vertical, the speed at $3.36 \mathrm{~km}$, just above the crest of the ridge, is also employed.

Three types of nuclei characteristics have been found:

1) The cyclic nature of the generator operations is seen in the nuclei data and can be related to a specific seeding period.

2) The nuclei count remains near 1 liter $^{-1}$ because of an inversion whose top is between the generator site and the observing site.

3) No increase in nuclei numbers are observed even though the wind velocity is proper for detection.

The absence of nuclei in Type III is hypothesized to be due to silver iodide nucleation of the orographic cloud.

Acknowledgments. This study was carried out as part of the Park Range Atmospheric Water Resources Program, conducted by E. Bollay Associates, Inc., for the U. S. Department of the Interior, Bureau of Reclamation, under Contract Number 14-06-D-5640.

\section{REFERENCES}

Auer, A. H., D. L. Veal and J. D. Marwitz, 1968: Plume tracking studies associated with orographic and convective situations. Proc. First Natl. Conf. Weather Modification, Albany, N. Y., 404-413. 
Boucher, R. J., 1956: Operation Overseed. Final Rept. to the Advisory Commission on Weather Control, Mt. Washington Observatory, $116 \mathrm{pp}$.

Fuquay, J. J., 1964: Progress in atmospheric physics: A summary of Hanford Laboratories work on this program under General Electric, 1959-1964. AEC Res. and Dev. Rept. HW-83602, $48 \mathrm{pp}$.

Hogan, A. W., and T. Rich, 1968: A mobile tracing technique utilizing a meteorologically inert lithium aerosol. Proc. Intern. Conf. Cloud Physics, Toronto, 45-49.
- C. E. Robertson, and C. P. Edwards, 1969: Application of an inert tracer to an AgI seeding experiment. J. Appl. Meteor., 8, 169-171.

Langer, G., J. Rosinski and C. P. Edwards, 1967: A continuous ice nucleus counter, and its application to tracking in the troposphere. J. Appl. Meteor., 6, 114-125.

Reinking, R. F., and L. O. Grant, 1968: The advection of artificial ice nuclei to mountain clouds from ground-based generators. Proc. First Natl. Conf. Weather Modification, Albany, N. Y. 433-445. 